\title{
Relative Importance of Basicity in the Gas Phase and in Solution for Determining Selectivity in Electrospray Ionization Mass Spectrometry
}

\author{
Brandie M. Ehrmann, ${ }^{a}$ Trine Henriksen, ${ }^{b}$ and Nadja B. Cech ${ }^{\mathrm{a}}$ \\ ${ }^{a}$ The University of North Carolina at Greensboro, Greensboro, North Carolina, USA \\ b Department of Clinical Pharmacology, Rigshospitalet, Copenhagen University Hospital, Copenhagen, Denmark
}

Electrospray ionization mass spectrometry is a critically important technique for the determination of small molecules, but its application for this purpose is complicated by its selectivity. For positive ion ESI-MS analysis of basic analytes, several investigators have pointed to the importance of analyte basicity as a source of selectivity. Currently, however, it is not known whether basicity in the gas phase or in solution is ultimately most important in determining responsiveness. The objective of these studies was to investigate the relative importance of basicity in solution and in the gas phase as factors that predict selectivity in positive ion ESI-MS analysis. ESI-MS response was compared for a diverse series of protonatable analytes in two different solvents, neat methanol and methanol with $0.5 \%$ acetic acid. A correlation was observed between analyte $\mathrm{pK}_{\mathrm{b}}$ and electrospray response. However, the response for the analytes with very high $\mathrm{pK}_{\mathrm{b}}$ values was significantly higher than would be expected based on concentration of the protonated form or the analyte in solution, and this higher response did not appear to result from gas-phase proton transfer reactions. Although all of the analytes investigated had higher gas-phase basicities than the solvent, their relative responses were not dictated by gas-phase basicity. Higher response was observed for all of the analytes studied in acidified methanol compared with neat methanol, and this higher response was most pronounced for weakly basic analytes. These findings support the use of analyte $\mathrm{pK}_{\mathrm{b}}$ for rational method development in ESI-MS analysis of small molecules. (J Am Soc Mass Spectrom 2008, 19, 719-728) (c) 2008 American Society for Mass Spectrometry

$\mathrm{O}$ ver the past several decades, electrospray has emerged as one of the leading ionization techniques for mass spectrometric determination of nonvolatile species. Its applicability for analysis of molecules of biological importance, combined with its suitability for interfacing on-line to chromatographic techniques, have made it an indispensable research tool. Nonetheless, electrospray is subject to some important limitations. It is relatively selective, and the presence of competing species in solution may cause significant signal suppression. An understanding of the factors that contribute to selectivity and signal suppression in analysis by electrospray ionization mass spectrometry (ESI-MS) is important for successful method development using this technique, particularly when it will be used in combination with high performance liquid chromatography (HPLC) for the analysis of complex mixtures.

A number of previous investigators have sought to understand the factors that determine responsiveness to ESI-MS analysis [1]. As might be expected, the ability of the analyte to become charged is of key importance [2].

Address reprint requests to Dr. Nadja Cech, Department of Chemistry and Biochemistry, The University of North Carolina Greensboro, P.O. Box 26170, Greensboro, NC 27402. E-mail: nadja_cech@uncg.edu
Molecules without an inherent charge can become ionized with ESI-MS in a number of ways. Ions can be formed by protonation or deprotonation, adduct formation, or electrolytic oxidation or reduction [1]. For the investigations here, the analytes of interest were a series of molecules that could be observed as the protonated species $\left(\mathrm{MH}^{+}\right)$in positive ion analysis. For such species, a number of investigators have predicted the obvious relationship between basicity in solution and electrospray response [3-5]. On the other hand, it is also acknowledged that gas-phase proton transfer can influence which molecules become charged in the ESI-MS process [4-8]. In a landmark paper, Ikonomou et al. sought to correlate electrospray response with analyte proton affinity in the gas phase and in solution [4]. In the Ikonomou investigation, it was observed that the electrospray response of a series of protonatable molecules was well correlated with analyte basicity in solution. However, because the gas-phase basicities of the analytes investigated were not known, it was difficult for a conclusion to be drawn as to how much gas-phase proton transfer contributed to charging the analytes of interest. Ikonomou and coworkers also hypothesized that decreasing solution $\mathrm{pH}$ should increase electrospray response of basic analytes. Such an effect was not, however, observed experimentally because the $\mathrm{HCl}$ 
used to adjust $\mathrm{pH}$ caused signal suppression. Thus, there is still a gap in the literature as to the relative importance of basicity in solution and in the gas phase for determining selectivity to positive ion ESI-MS analysis of small molecules. This lack of knowledge is a problem because it prevents the rationale optimization of electrospray conditions based on a knowledge of how charging takes place.

Our objective in the investigations described herein was to gain insight into the relative importance of gas-phase and solution-phase basicity for determining the selectivity of a series of structurally diverse analytes to analysis with ESI-MS (Scheme 1). To accomplish this objective, we tested the hypothesis that for the analysis of protonatable molecules in the positive ion mode, the molecule's ability to be charged in solution should be a key determining factor in its responsiveness. To test this hypothesis, we measured electrospray response for equimolar concentrations of a series of analytes with known $\mathrm{pK}_{\mathrm{b}}$ and gas-phase basicities in neat and acidified methanol. The experimentally determined electrospray response for each analyte was compared with the calculated concentration of its protonated form in solution. Acetic acid was used to acidify the methanol solution to circumvent the problem of signal suppression observed previously by Ikonomou et al. [4], and knowledge of gas-phase basicities of the analytes stud-<smiles>NCCc1ccccc1</smiles>

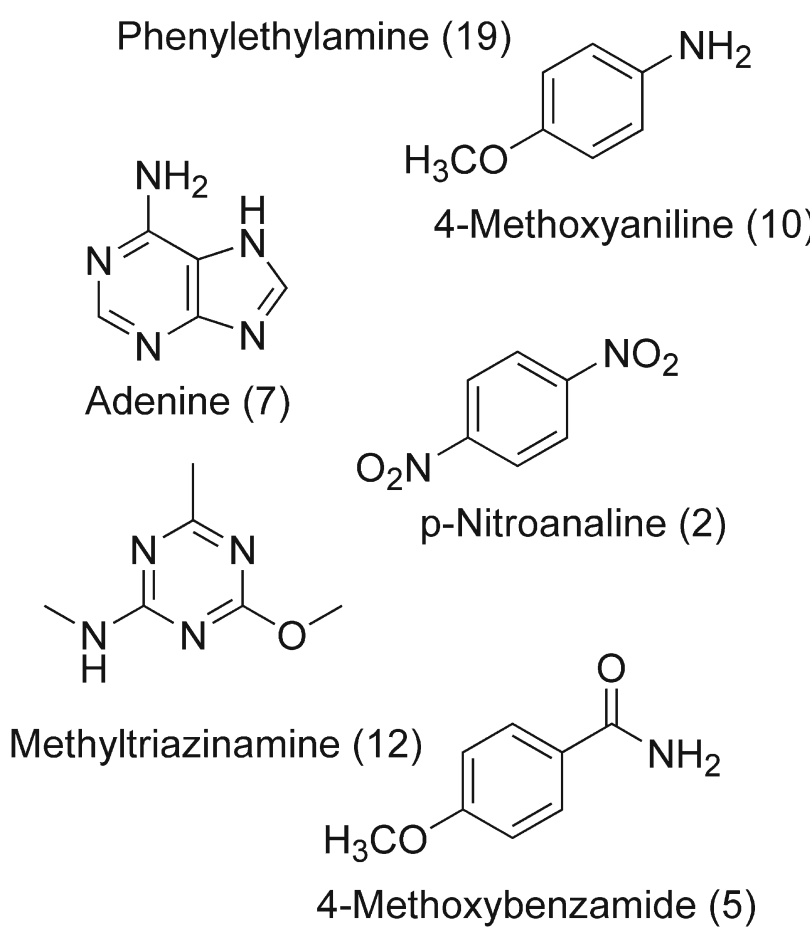

Scheme 1. Structures of selected analytes investigated in this study. The electrospray responses and some selected physiochemical properties of these analytes are displayed in Table 1. ied facilitated interpretation of the results in terms of the relative importance of proton transfer in solution and in the gas phase. The results of this study provide new insight into the usefulness and limitations of analyte $\mathrm{pK}_{\mathrm{b}}$ as a predictor of responsiveness to analysis with positive ion ESI-MS. An understanding of the relationship between analyte $\mathrm{pK}_{\mathrm{b}}$ and responsiveness to ESI-MS analysis is very useful for method development with this technique; therefore, these results are significant to users of ESI-MS.

\section{Experimental}

\section{Chemicals}

Reagent grade standards were all purchased from Sigma Aldrich (St. Louis, MO). Analytes chosen were those commercially available for which $\mathrm{pK}_{\mathrm{a}}$ and gasphase basicity were known. It was also important that all analytes be similar in mass, to avoid complications with mass dependent transmission in the mass spectrometer. All analytes investigated were in the molecular weight range of 100 to $170 \mathrm{Da}$.

Purity of the chemicals employed in the study ranged from $97 \%$ to $99+\%$. Stock solutions were prepared at $0.010 \mathrm{M}$ in neat methanol and serial dilutions were carried out in methanol to a final concentration of $1.0 \times 10^{-4} \mathrm{M}$. HPLC grade solvents were used for solution preparation and all analyses. The chemicals in this study are hazardous to human health and should be handled with proper protection and ventilation to prevent inhalation or contact with skin or eyes.

\section{ESI-MS Analysis}

Analyses were conducted using a ThermoFinnigan LCQ Advantage Ion Trap Mass Spectrometer (San Jose, CA) equipped with a nanoelectrospray source. A fused silica spray capillary with a $50 \mu \mathrm{m}$ i.d. was employed (New Objective, Woburn, MA). The instrument lens voltages were optimized at $\mathrm{m} / \mathrm{z} 195.0$ (caffeine). The spray voltage was set at $1.5 \mathrm{kV}$, and the capillary temperature at $150{ }^{\circ} \mathrm{C}$. A potential of $14 \mathrm{~V}$ was applied to the capillary and the tube lens offset was $55.0 \mathrm{~V}$. The scan range was from $\mathrm{m} / \mathrm{z} 50$ to 400 .

An Agilent 1100 Series capillary HPLC System (Agilent, Santa Clara, CA) with micro autosampler was interfaced to the mass spectrometer and used for the flow injection analyses. The HPLC was operated with a flow solvent of either $100 \%$ methanol or methanol with $0.5 \%$ glacial acetic acid depending on the application. A flow rate of $10 \mu \mathrm{L} / \mathrm{min}$ and an injection volume of $5 \mu \mathrm{L}$ were used.

\section{Data Analysis}

The responsiveness of a given analyte was determined for each flow injection analysis as the area of the selected ion trace corresponding to the $\mathrm{MH}^{+}$ion of the 
analyte of interest. The average response of each analyte ion was calculated from triplicate analyses. All of the analyses were performed in a single run (during one $24 \mathrm{~h}$ period) to minimize error that could be introduced by run-to-run fluctuation in instrumental response.

For the analytes listed in Table $1, \mathrm{pK}_{\mathrm{a}}$ values were calculated for methanol solution by adding 0.6 to the NIST Web Book [9] $\mathrm{pK}_{\mathrm{a}}$ value for each analyte in aqueous solution. This approximate approach for calculating methanolic $\mathrm{pK}_{\mathrm{a}}$ based on aqueous $\mathrm{pK}_{\mathrm{a}}$ has previously been employed by Kebarle and coworkers [4]. From the calculated methanolic $\mathrm{pK}_{\mathrm{a}}$ values, the relationship $\mathrm{pK}_{\mathrm{a}} \mathrm{pK}_{\mathrm{b}}=\mathrm{K}_{\mathrm{SH}}$ was used to calculate $\mathrm{pK}_{\mathrm{b}}$ values. Log P-values were calculated for the neutral species using the molecular modeling program ChemSketch (Advanced Chemistry Development, Toronto, Ontario). Gas-phase basicities, where available, were obtained from the NIST Web Book [9].

\section{Theory}

To understand the possible significance of gas-phase and solution-phase proton transfer reactions in ESIMS, it is useful to first consider the mechanism by which ESI occurs. In the ESI process, the sample solution is pumped through a narrow capillary (the spray capillary) at a flow rate ranging from a few $\mathrm{nL}$ per min to hundreds of $\mu \mathrm{L}$ per min depending on the application. A high voltage (generally in the range $2-5 \mathrm{kV}$ ) is applied to this capillary, generating an electric field gradient between the capillary and the counter-electrode (the entrance to the mass spectrometer, which is at a much lower voltage than the spray capillary). As a consequence of this applied voltage, ions in the solution are separated from their counterions and undergo electrophoretic migration. Ions of the same polarity as the applied voltage are repelled from the charged spray capillary, causing the solution to project from the tip of the capillary in the form of a cone (the Taylor cone). The Coulombic repulsion of multiple charges on the surface of this Taylor cone eventually overcomes the surface tension of the solution, causing a series of droplets to be ejected. These droplets contain the excess charge that was created as a consequence of electrophoretic migration in the electric field. After the droplets are formed, they continue to migrate towards the entrance to the mass spectrometer, all the while shrinking as the solvent evaporates. When the droplets have shrunk enough that the repulsion of the charges on their surfaces again overcomes the liquid surface tension, they become unstable and eject a series of even smaller droplets. This process continues until free, gas-phase ions are formed. Ion formation has been postulated to occur by one of two mechanisms. Either the droplets undergo enough fissions that they eventually consist of single ions [10], or the Coulombic repulsion caused by the excess charges on the surfaces of the very small droplets causes ions to "evaporate" into the gas phase [11]. Regardless of how they are produced, the ESI process ultimately serves to provide ions that can be sampled by the mass spectrometer.

Table 1. Relevant properties and electrospray response of the analytes studied

\begin{tabular}{|c|c|c|c|c|c|c|c|}
\hline \# & Compound & $\mathrm{mw}$ & $\mathrm{pK}_{\mathrm{a}}(\mathrm{MeOH})^{\mathrm{a}}$ & $\mathrm{pK}_{\mathrm{b}}(\mathrm{MeOH})^{\mathrm{b}}$ & Response $^{c}$ & $\log P^{d}$ & $\mathrm{~GB}(\mathrm{KJ} / \mathrm{mol})^{\mathrm{e}}$ \\
\hline 1 & Thymine & 126.11 & -1.01 & 17.5 & 0 & -1.00 & 850.0 \\
\hline 2 & p-Nitroaniline & 138.12 & 1.60 & 14.9 & $6.90 \times 10^{7}$ & 1.37 & 834.2 \\
\hline 3 & Benzamide & 121.05 & -0.94 & 17.4 & $8.71 \times 10^{7}$ & 0.74 & 861.2 \\
\hline 4 & Diphenylamine & 169.22 & 1.38 & 15.1 & $4.69 \times 10^{8}$ & 2.97 & \\
\hline 5 & 4-Methoxybenzamide & 151.16 & -0.61 & 17.1 & $5.10 \times 10^{8}$ & 0.81 & 869.4 \\
\hline 6 & Cytosine & 111.10 & 5.20 & 11.3 & $7.25 \times 10^{8}$ & -2.29 & 918.0 \\
\hline 7 & Adenine & 135.13 & 3.55 & 13.0 & $1.20 \times 10^{9}$ & -0.03 & 912.5 \\
\hline 8 & N-ethylaniline & 121.18 & 5.72 & 10.8 & $1.29 \times 10^{9}$ & 2.13 & 892.9 \\
\hline 9 & 2-Methoxyaniline & 123.15 & 5.12 & 11.4 & $4.42 \times 10^{9}$ & 1.09 & 873.3 \\
\hline 10 & 4-Methoxyaniline & 123.15 & 5.96 & 10.5 & $4.96 \times 10^{9}$ & 0.74 & 868.5 \\
\hline 11 & 2,2 Bipyridine & 156.18 & 4.95 & 11.6 & $6.80 \times 10^{9}$ & 1.28 & \\
\hline 12 & Methyltriazinaminec & 154.17 & 3.73 & 12.8 & $7.01 \times 10^{9}$ & -1.34 & \\
\hline 13 & Benzylamine & 107.15 & 10.00 & 6.5 & $7.97 \times 10^{9}$ & 1.09 & 879.4 \\
\hline 14 & Triethanolamine & 149.19 & 8.36 & 8.1 & $1.03 \times 10^{10}$ & -0.74 & \\
\hline 15 & Triethylamine & 101.19 & 11.31 & 5.2 & $1.17 \times 10^{10}$ & 1.66 & 951.0 \\
\hline 16 & $N$-methylbenzylamine & 121.18 & 10.35 & 6.2 & $1.35 \times 10^{10}$ & 1.60 & \\
\hline 17 & Quinuclidine & 111.18 & 11.71 & 4.8 & $1.37 \times 10^{10}$ & 1.38 & 952.5 \\
\hline 18 & $N, N$-dimethylbenzylamine & 135.21 & 9.40 & 7.1 & $1.56 \times 10^{10}$ & 1.98 & 937.4 \\
\hline 19 & Phenylethylamine & 121.18 & 10.50 & 6.0 & $2.17 \times 10^{10}$ & 1.49 & 902.3 \\
\hline
\end{tabular}

${ }^{a} \mathrm{pK}_{\mathrm{a}}$ values were calculated by adding 0.6 to the aqueous pK $\mathrm{a}_{\mathrm{a}}$ values published in the NIST Chemistry Webbook (http://webbook.nist.gov/

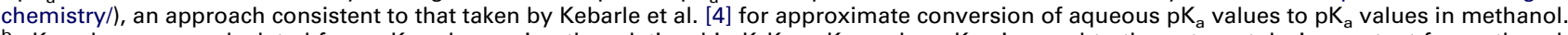
${ }^{b} \mathrm{pK}_{\mathrm{b}}$ values were calculated from $\mathrm{pK}_{\mathrm{a}}$ values using the relationship $\mathrm{K}_{\mathrm{a}} \mathrm{K}_{\mathrm{b}}=\mathrm{K}_{\mathrm{SH}}$, where $\mathrm{K}_{\mathrm{SH}}$ is equal to the autoprotolysis constant for methanol, $3.2 \times 10^{-17}[12]$.

${ }^{c}$ Response represents the average under the curve for the selected ion trace of the $\mathrm{MH}^{+}$ion for the analyte of interest. Averages were calculated for triplicate analyses.

${ }^{\mathrm{d}}$ logP values were calculated using Chemsketch (ACD development, Toronto, ON).

${ }^{\text {e }}$ Gas phase basicity (GB) values, where available, were obtained from the NIST Chemistry Webbook [9]. 
Any mass spectrometric technique requires that the analyte be charged. All of the analytes investigated here were chargeable through protonation, and were detected as protonated molecular ions. Protonation of the analyte could, however, have occurred either in the bulk solution, in the electrospray droplets, or in the gas phase after molecules had been liberated from the electrospray droplets. One of the goals of our study was to examine the relationship between electrospray responsiveness and analyte basicity, both in solution and in the gas phase. Such an investigation would provide insight into whether or not protonation in electrospray occurs primarily in solution. Toward that objective, the following discussion lays out some of the theoretical predictions of the relationship between response and $\mathrm{pK}_{\mathrm{b}}$, and response and gas-phase basicity (GB). The measurements made in these studies were conducted in the common electrospray solvent methanol, so the discussion of the theory in this section will focus on reactions that occur in that solvent.

\section{Predicted Relationship Between ESI-MS Response and Basicity in Solution}

The following equation (eq 1) describes the reaction that occurs when the neutral form of a basic analyte (B) is dissolved in methanol solvent. The products are methoxide ion $\left(\mathrm{CH}_{3} \mathrm{O}^{-}\right)$and protonated analyte $\left(\mathrm{BH}^{+}\right)$. The $\mathrm{BH}^{+}$form of the analyte can be detected by the mass spectrometer. Thus, at least based on the chemistry that occurs in solution, the extent to which products are favored in eq 1 should predict how responsive a given analyte will be to analysis with ESI-MS. The extent that products are thermodynamically favored in eq 1 is described by the magnitude of $\mathrm{K}_{\mathrm{b}}$, the equilibrium constant for the reaction (eq 2). A high $\mathrm{K}_{\mathrm{b}}$ value (low $\mathrm{pK}_{\mathrm{b}}$ ) will indicate that products should be favored, and that the analyte should be very responsive to analysis with ESI-MS. A low $\mathrm{K}_{\mathrm{b}}$ value (high $\mathrm{pK}_{\mathrm{b}}$ ), on the other hand, will indicate that the analyte remains preferentially in its neutral state in methanol solvent, making it a poor candidate for ESI-MS analysis. It should be noted that the magnitude of $K_{b}$ is dependent on which solvent is being used.

$$
\begin{aligned}
& \mathrm{B}+\mathrm{CH}_{3} \mathrm{OH} \rightleftharpoons \mathrm{BH}^{+}+\mathrm{CH}_{3} \mathrm{O}^{-} \\
& \mathrm{K}_{\mathrm{b}}=\frac{\left[\mathrm{CH}_{3} \mathrm{O}^{-}\right]\left[\mathrm{BH}^{+}\right]}{[\mathrm{B}]}
\end{aligned}
$$

One of the goals of this study is to investigate the relationship between analyte basicity in solution and electrospray response. Assuming that electrospray response is related to $\left[\mathrm{BH}^{+}\right]$, eq 3 facilitates a quantitative prediction of this relationship. This equation is derived by substituting $\left[\mathrm{BH}^{+}\right]$for $\left[\mathrm{CH}_{3} \mathrm{O}^{-}\right]$and $\left(\mathrm{C}_{\mathrm{i}}-\left[\mathrm{BH}^{+}\right]\right)$for $[\mathrm{B}]$ in eq 2. In eq $3, C_{i}$ represents the formal concentration of analyte.

$$
\left[\mathrm{BH}^{+}\right]^{2}+\mathrm{K}_{\mathrm{b}}\left[\mathrm{BH}^{+}\right]-\mathrm{K}_{\mathrm{b}} \mathrm{C}_{\mathrm{i}}=0
$$

If eq 3 is solved for $\left[\mathrm{BH}^{+}\right]$using the quadratic equation, a plot of $\left[\mathrm{BH}^{+}\right]$versus $\mathrm{pK}_{\mathrm{b}}$ can be generated (solid line in Figure 1). If the only factor determining responsiveness of basic analytes to ESI-MS analysis were the ability of these analytes to be protonated in solution, a plot of analyte response versus analyte $\mathrm{pK}_{\mathrm{b}}$ would be expected to resemble the solid line in Figure 1.

In deriving eq 3 , the assumption is made that any contribution of autoprotolysis of methanol (eq 4) to the equilibrium concentration of methoxide can be ignored. This assumption is justified based on the very low autoprotolysis constant of methanol $\left(\mathrm{K}_{\mathrm{SH}}\right.$, eq 5), which has a published value of $3.2 \times 10^{-17}$ [12].

$$
\begin{aligned}
& 2 \mathrm{CH}_{3} \mathrm{OH} \rightleftharpoons \mathrm{CH}_{3} \mathrm{O}^{-}+\mathrm{CH}_{3} \mathrm{OH}_{2}^{+} \\
& \mathrm{K}_{\mathrm{SH}}=\left[\mathrm{CH}_{3} \mathrm{O}^{-}\right]\left[\mathrm{CH}_{3} \mathrm{OH}_{2}^{+}\right]
\end{aligned}
$$

\section{Predicted Effect of Acidifying the Analyte Solution}

For electrospray ionization mass spectrometric analyses in the positive ion mode, it is typical to add a weak, volatile acid to the analyte solution. The rationale behind this practice is that the addition of acid, by making the solution more acidic, facilitates protonation of the analyte. It was of interest in this study to predict the magnitude of change in analyte response that could

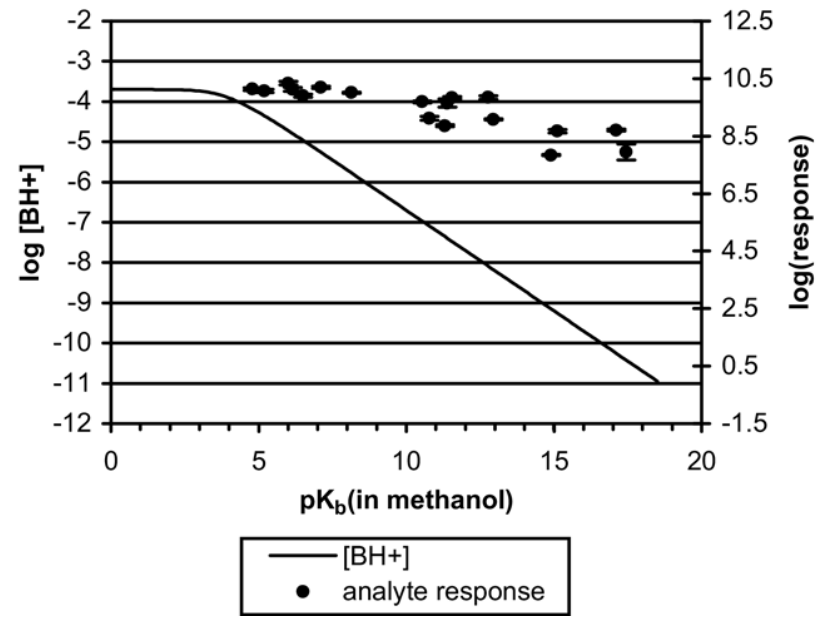

Figure 1. Relationship between ESI-MS response and analyte $\mathrm{pK}_{\mathrm{b}}$. Each analyte was injected individually at a concentration of $100 \mu \mathrm{M}$ in neat methanol, and the response was calculated by measuring the area under the flow injection peak for the $\mathrm{MH}^{+}$ion of the relevant analyte. Mean response values were calculated for triplicate injections, and the error bars represent \pm 1 standard deviation. The solid line represents the concentration of the analyte in the bulk solution calculated using eq 3 , which is derived from the thermodynamic equilibrium constant expression. For this equation, the initial concentration of analyte $\left(\mathrm{C}_{\mathrm{i}}\right)$ corresponds to the experimental concentration of $100 \mu \mathrm{M}$ and the value of the autoprotolysis constant for methanol $\left(\mathrm{K}_{\mathrm{SH}}\right)$ was taken as the literature value of $3 \times 10^{-17}$ [12]. 
be expected to occur by addition of $0.5 \%$ acetic acid to a methanolic solution. Such predictions are important for the sake of comparison between observed and experimentally predicted response in acidified and neutral solvent.

In a solution of methanol with added acetic acid, the equilibrium reactions in eqs 1 and 4 will occur. In addition, a third reaction will take place, that of the added acid transferring a proton to methanol. This reaction is shown in eq 6, where $\mathrm{CH}_{3} \mathrm{COOH}$ is acetic acid. The published value for the equilibrium constant for this reaction $\left(\mathrm{K}_{\mathrm{a}, \mathrm{CH}} \mathrm{COOH}\right.$ in eq 7$)$ is $\sim 2.3 \times 10^{-10}$ [13].

$$
\begin{aligned}
& \mathrm{CH}_{3} \mathrm{COOH}+\mathrm{CH}_{3} \mathrm{OH} \rightleftharpoons \mathrm{CH}_{3} \mathrm{OH}_{2}^{+}+\mathrm{CH}_{3} \mathrm{COO}^{-} \\
& \mathrm{K}_{\mathrm{a}, \mathrm{CH}_{3} \mathrm{COOH}}=\frac{\left[\mathrm{CH}_{3} \mathrm{COO}^{-}\right]\left[\mathrm{CH}_{3} \mathrm{OH}_{2}^{+}\right]}{\left[\mathrm{CH}_{3} \mathrm{COOH}\right]}
\end{aligned}
$$

To derive a relationship between $\mathrm{K}_{\mathrm{b}}$ and $\left[\mathrm{BH}^{+}\right]$for $\mathrm{a}$ basic analyte dissolved in acidified methanol, it is useful to start with the proton balance equation (eq 8). This proton balance equation is based on the species present in the equilibrium reactions shown in eqs 1,4 , and 6.

$$
\left[\mathrm{CH}_{3} \mathrm{OH}_{2}^{+}\right]+\left[\mathrm{BH}^{+}\right]=\left[\mathrm{CH}_{3} \mathrm{COO}^{-}\right]+\left[\mathrm{CH}_{3} \mathrm{O}\right]
$$

In methanol with $0.5 \%$ acetic acid, the $\left[\mathrm{CH}_{3} \mathrm{O}^{-}\right]$is small enough relative to the other terms to be neglected in the proton balance equation under practical conditions. Neglecting this term and substituting the appropriate terms from the equilibrium expressions (eqs 5 and 7) into eq 8 gives eq 9. In eq $9, K_{b}$ is equal to the equilibrium constant for the analyte acting as a base in methanol (eq 2), $\mathrm{K}_{\mathrm{a}, \mathrm{CH}_{3} \mathrm{COOH}}$ is equal to the equilibrium constant for protonation of methanol by acetic acid (eq $7), \mathrm{K}_{\mathrm{SH}}$ is equal to the autoprotolysis constant for methanol (eq 5), $C_{i}$ is equal to the formal concentration of the analyte, and $\mathrm{F}$ is equal to the formal concentration of acetic acid.

$$
\begin{aligned}
& \mathrm{K}_{\mathrm{b}}\left[\mathrm{CH}_{3} \mathrm{OH}_{2}^{+}\right]^{3}+\left(\mathrm{K}_{\mathrm{SH}}+\mathrm{K}_{\mathrm{b}} \mathrm{C}_{\mathrm{i}}\right)\left[\mathrm{CH}_{3} \mathrm{OH}_{2}^{+}\right]^{2}
\end{aligned}
$$

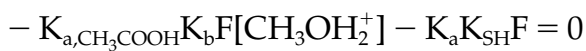

Equation 9 can be solved for $\left[\mathrm{CH}_{3} \mathrm{OH}_{2}{ }^{+}\right]$for any given value of $\mathrm{K}_{\mathrm{b}}$ using a polynomial equation solver. It is then possible to convert from $\left[\mathrm{CH}_{3} \mathrm{OH}_{2}{ }^{+}\right]$to $\left[\mathrm{BH}^{+}\right]$ using eq 10 (which is derived from eqs 2 and 5).

$$
\left[\mathrm{BH}^{+}\right]=\frac{\mathrm{K}_{\mathrm{b}} \mathrm{C}_{\mathrm{i}}\left[\mathrm{CH}_{3} \mathrm{OH}_{2}^{+}\right]}{\mathrm{K}_{\mathrm{b}}\left[\mathrm{CH}_{3} \mathrm{OH}_{2}^{+}\right]+\mathrm{K}_{\mathrm{SH}}}
$$

Using eqs 9 and 10, a plot of $\left[\mathrm{BH}^{+}\right]$as a function of analyte $\mathrm{pK}_{\mathrm{b}}$ for a solution of methanol with $0.5 \%$ acetic acid can be generated. Such a plot is presented in the Results and Discussion section for the purpose of comparison with experimental data.

\section{Predicted Relationship Between ESI-MS Response and Gas Phase Basicity}

Ions that have been liberated from the ESI droplets remain for a short period of time at atmospheric pressure within the ion source before being sampled by the mass spectrometer. During this period, gas-phase proton transfer reactions can occur [4]. Gas-phase proton transfer reactions are important in ESI-MS analysis because a molecule's basicity in solution can be very different from its basicity in the gas phase. Consequently, it is not always true that the molecule that is most basic in solution is the one that ends up being detected in the final positive ion ESI-MS analysis. This is true in the case of water and methanol. Water is more basic than methanol in solution, but in the gas phase, methanol is a stronger base than is water. (The gasphase basicities of methanol and water are 724.5 and $660.0 \mathrm{~kJ} / \mathrm{mol}$, respectively [9]). For this reason, in positive ion electrospray analysis of acidic water/methanol mixtures, the observed mass spectra show clusters of protonated methanol (the stronger gas-phase base) and not of water, even in cases where the methanol content in the solution is quite low [6]. This observation has been rationalized on the basis of proton transfer reactions from the water to the methanol in the gas phase at atmospheric pressure in the ion source, and is often used as an example to indicate the potential important influence of gas-phase proton transfer reactions on electrospray response.

Volatile solvents are typically employed in ESI-MS analyses, and these solvents are present in excess. Thus, the region in which the electrospray process takes place would be expected to contain an abundance of vaporphase solvent molecules. If gas-phase proton transfer reactions between the analyte and this solvent were kinetically favorable, these reactions could influence ESI-MS response. The expected influence of such proton transfer reactions on ESI-MS response could be either enhancement or suppression of analyte response, depending on the relative gas-phase basicity of the analyte compared with that of the solvent.

Suppression of electrospray response in the positive ion mode could occur if the gas-phase basicity of the analyte of interest was lower than the solvent or solvent additives. In this case, protons could be transferred from the analyte to the solvent, yielding a neutral and undetectable analyte. Such a case has been demonstrated for analysis of an analyte with low gas-phase basicity in a solvent with higher gas-phase basicity [6]. Fortunately, most basic organic molecules investigated with ESI-MS have higher gas-phase basicities than the typical ESI solvents (methanol, water, and acetonitrile); thus, their response would not be suppressed by proton transfer to the solvent.

An important caveat in the preceding discussion of how gas-phase basicity might be related to electrospray response is that analytes are still solvated when released by electrospray droplets, and, depending on the 
design of the ESI source, may not become desolvated until they pass into the first low vacuum chamber of the mass spectrometer. Thus, the gas-phase basicity of the solvated analyte rather than the published value for the bare analyte should determine its ability to undergo gas-phase proton transfer reactions in ESI-MS. In addition, common electrospray solvents such as water and methanol are often detected as protonated clusters rather than as single protonated solvent molecules after ESI-MS analysis [6]. These clusters may not exist at high abundance at atmospheric pressure. However, the presence of some solvent clusters as opposed to only single protonated solvent molecules would further complicate the prediction of likelihood of proton transfer on the basis of gas-phase basicities. Ultimately, any such predictions are approximations, but could still be useful for qualitative purposes.

It has often been proposed in the electrospray literature that gas-phase proton transfer could facilitate protonation (and, therefore, detection) of the analyte of interest by positive ion ESI-MS [4]. Such an enhancement could take place as follows. If neutral analytes (B) were liberated from ESI droplets, they could become charged by transfer of protons from some acidic species in the gas phase $\left(\mathrm{SH}^{+}\right)$as indicated in eq 11. The species $\mathrm{SH}^{+}$in eq 11 could be protonated solvent or any high abundance additive with lower gas-phase basicity than the solvated analyte.

$$
\mathrm{B}(\mathrm{g})+\mathrm{SH}^{+}(\mathrm{g}) \leftrightarrow \mathrm{BH}^{+}(\mathrm{g})+\mathrm{S}(\mathrm{g})
$$

In order for response to be enhanced by proton transfer, several conditions would have to be met. First, the neutral analytes would have to be able to escape the electrospray droplets. Second, sufficient quantities of a proton donor $\left(\mathrm{SH}^{+}\right)$would have to be available in the gas phase to react with the analyte. For analysis in methanolic solutions, protonated methanol could be expected to serve as the proton transfer reagent. The relatively low gas-phase proton affinity of methanol with respect to typical analytes would be expected to favor reactions such as that shown in eq 11, with $\mathrm{CH}_{3} \mathrm{OH}_{2}{ }^{+}$serving as the source of protons. In neat methanol solutions, the $\mathrm{CH}_{3} \mathrm{OH}_{2}{ }^{+}$necessary to facilitate such reactions could be formed by autoprotolysis of the solvent or by electrolysis at the electrical contact to the spray capillary [14]. In the latter case, electrolysis of the trace levels of water that undoubtedly exist even in "pure" methanol solutions could create hydronium ions that would subsequently react to form protonated methanol. In methanol solutions acidified with acetic acid, an even greater quantity of protonated methanol would be present due to the reaction of neutral methanol with acetic acid.

\section{Results and Discussion}

Physical properties and electrospray responses for the 19 test compounds investigated in these studies are displayed in Table 1. All of the compounds investigated were protonatable, and the response for each of them represents that of the $\mathrm{MH}^{+}$ion monitored in the positive ion mode. Thus, $\mathrm{pK}_{\mathrm{b}}$ values are an indicator of the ability of the molecule to become charged in solution (eq 1) because addition of a proton results in the formation of a positively charged ion.

It is obvious from Table 1 that the analytes investigated here had widely different electrospray responses. Although the solution concentration of each analyte investigated was the same $(100 \mu \mathrm{M})$, there was a 300 -fold range in response between the least responsive (but still detectable) and most responsive analyte (Table 1). The following is a discussion of how various physiochemical parameters of the analytes correlate with these differences in response.

\section{Relationship Between Electrospray Response and Predicted Concentration of Protonated Analyte in Solution}

A plot of the log of the experimentally measured response of each analyte versus its $\mathrm{pK}_{\mathrm{b}}$ is shown in Figure 1. The data were plotted in a log plot to facilitate visualization of responses that spanned several orders of magnitude. The data points represent the mean of triplicate measurements of electrospray responses for the analytes investigated. The solid line represents the $\log$ of the concentration of protonated analyte predicted to exist in solution as a function of $\mathrm{pK}_{\mathrm{b}}$. These predicted values are based on thermodynamic equilibrium calculations (eq 3) as described in the Theory section.

The general shape of the experimentally measured response curve (Figure 1) resembles that of the predicted curve. Response is at a maximum for the more strongly basic analytes (those with low $\mathrm{pK}_{\mathrm{b}}$ values), for which the protonated form of the analyte would be favored in solution. For analytes with higher $\mathrm{pK}_{\mathrm{b}}$ values (less basic analytes), response decreases linearly as a function of $\mathrm{pK}_{\mathrm{b}}$. However, clearly the experimental curve has a shallower slope than that of the predicted curve. This shallow slope means that for the analytes with very high $\mathrm{pK}_{\mathrm{b}}$ values, response is much higher than would be predicted based solely on concentration in solution. For example, Compound 3, benzamide, has a $\mathrm{pK}_{\mathrm{b}}$ in methanol of 17.4 (Table 1). Based on this $\mathrm{pK}_{\mathrm{b}}$ value, the bulk concentration of protonated benzamide would be predicted to be $2 \times 10^{-11} \mathrm{M}$ (eq 3), well below the detection limits of a typical electrospray ionization ion trap mass spectrometer such as the ThermoFinnigan instrument employed for these investigations. Fortunately, however, apparently a greater concentration of protonated analyte is produced by the ESI-MS process than that which can be predicted based on the bulk solution concentration, facilitating detection of poorly basic analytes.

One possible reason for the differences in the observed and predicted curves in Figure 1 is inaccuracies 
in the $\mathrm{pK}_{\mathrm{b}}$ values calculated for methanol based on aqueous $\mathrm{pK}_{\mathrm{a}}$ values. The use of $\mathrm{pK}_{\mathrm{b}}$ (or $\mathrm{pK}_{\mathrm{a}}$ ) values measured for methanol would be more accurate, but such values are not available for the analytes investigated. However, while inaccuracies in $\mathrm{pK}_{\mathrm{b}}$ values could partially contribute to the lack of agreement among the predicted and experimental curves in Figure 1, it seems unlikely that such a dramatic and consistent difference would be observed throughout the range of analyte $\mathrm{pK}_{\mathrm{b}}$ values. Rather, it is more likely that some effect inherent to the ESI process favors protonation of the analyte to a greater extent than would occur in the bulk solution. A simple explanation is that the analyte solution becomes acidified by the electrospray process. Indeed, electrospray droplets generated by positive ion ESI-MS have been determined to be several $\mathrm{pH}$ units lower than the bulk solution $[15,16]$. This enhancement in acidity can be explained on the basis of electrolysis of the electrospray solvent [15] and/or enrichment of the electrospray droplets in protonated solvent due to charge separation that is part of the electrospray process [16].

\section{Influence of Solution pH on Electrospray Response}

Given the observed correlation between ESI-MS response and analyte $\mathrm{pK}_{\mathrm{b}}$, it was of interest to determine how analyte response changed in acidified solution. If solution phase chemistry is, indeed, key in determining responsiveness to ESI-MS analysis, an increase in acidity of the analyte solution would be expected to improve the response of poorly basic analytes (those with high $\mathrm{pK}_{\mathrm{b}}$ values), as discussed in the Theory section. Such an effect was predicted by Ikonomou et al. [4], but the use of $\mathrm{HCl}$ to acidify the analyte solution caused signal suppression, so the expected signal enhancement in acidic solutions was not observed. For our studies, acetic acid was employed for acidification to circumvent the problem of signal suppression. Other investigators have previously observed changes in electrospray response upon acidifying the analyte solution with acetic acid [17, 18]. The studies presented here are, however, unique in that the observed responses in acidified and neat methanol are compared with the calculated concentration of the protonated form of the analyte in each solution.

A subset of the compounds from Table 1 was chosen to investigate the influence of methanol acidification on electrospray response, and the response of these analytes was compared in neat methanol and methanol acidified with acetic acid (Figure 2). The subset of analytes for this investigation was chosen to span a range of $\mathrm{pK}_{\mathrm{b}}$ values. Individual analytes in the various $\mathrm{pK}_{\mathrm{b}}$ ranges were selected at random and the selection process was not based on knowledge of how the analytes would respond to the analysis. While it would have been preferable to compare response in neat and acidified methanol for all of the species in Table 1, the long run times necessary to accomplish triplicate anal-

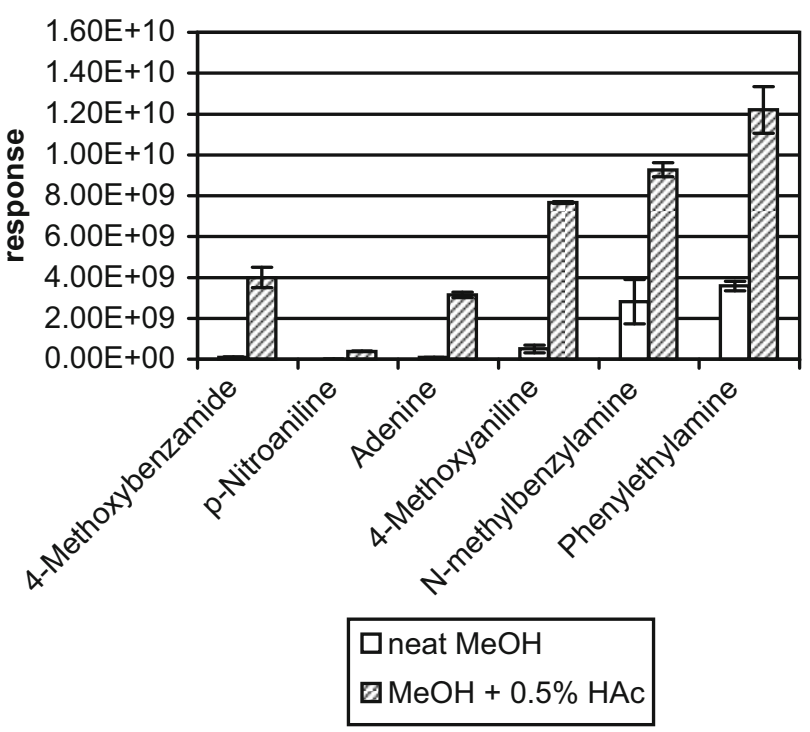

Figure 2. Influence of electrospray solvent acidity on responsiveness. A subset of molecules from Table 1 was analyzed for this experiment. Each analyte was analyzed separately in two different solvents, neat methanol and 99.5\% methanol:0.5\% acetic acid. Clearly, the addition of acetic acid to the solvent enhances the response of the analytes studied, and this enhancement is greater (relative to the total response) for analytes that respond poorly than for those that are highly responsive.

yses of 19 analytes in two different solvent systems were not feasible on the ion trap mass spectrometer used for these studies due to instability in instrument response.

It is clear from Figure 2 that, as would be expected, the addition of acetic acid to the methanol spray solvent increases the response of all of the analytes investigated. The observed increase in response can be compared with the predicted increase using a plot of response versus $\mathrm{pK}_{\mathrm{b}}$. Such a plot is shown in Figure 3. Figure $3 a$ shows the log of the predicted concentration of protonated analyte as a function of $\mathrm{pK}_{\mathrm{b}}$ in neat methanol (solid line, from eq 3 ) and methanol with $0.5 \%$ acetic acid (dotted line, from eqs 9 and 10). The observed relationship between response and $\mathrm{pK}_{\mathrm{b}}$ in neat methanol and acidified methanol is displayed in Figure $3 b$, where the numbers next to the data points refer to the compound identifications in Table 1. The data in Figure $3 \mathrm{~b}$ are the same as those displayed in Figure 2, but they are plotted with a scatter plot to emphasize the relationship between response and $\mathrm{pK}_{\mathrm{b}}$.

The predicted curves in Figure 3a suggest that acidification of the solvent should increase the response for analytes with high $\mathrm{pK}_{\mathrm{b}}$ values, but that the increase will not be observed for the most basic analytes (those with lowest $\mathrm{pK}_{\mathrm{b}}$ values). Qualitatively, this means that the predicted curves for neat and acidified methanol converge at low $\mathrm{pK}_{\mathrm{b}}$ values. This convergence occurs because the protonated form of the most basic analytes is favored even in neat methanol solution. Thus, the addition of acetic acid has no effect on what fraction of these basic analytes is protonated. 

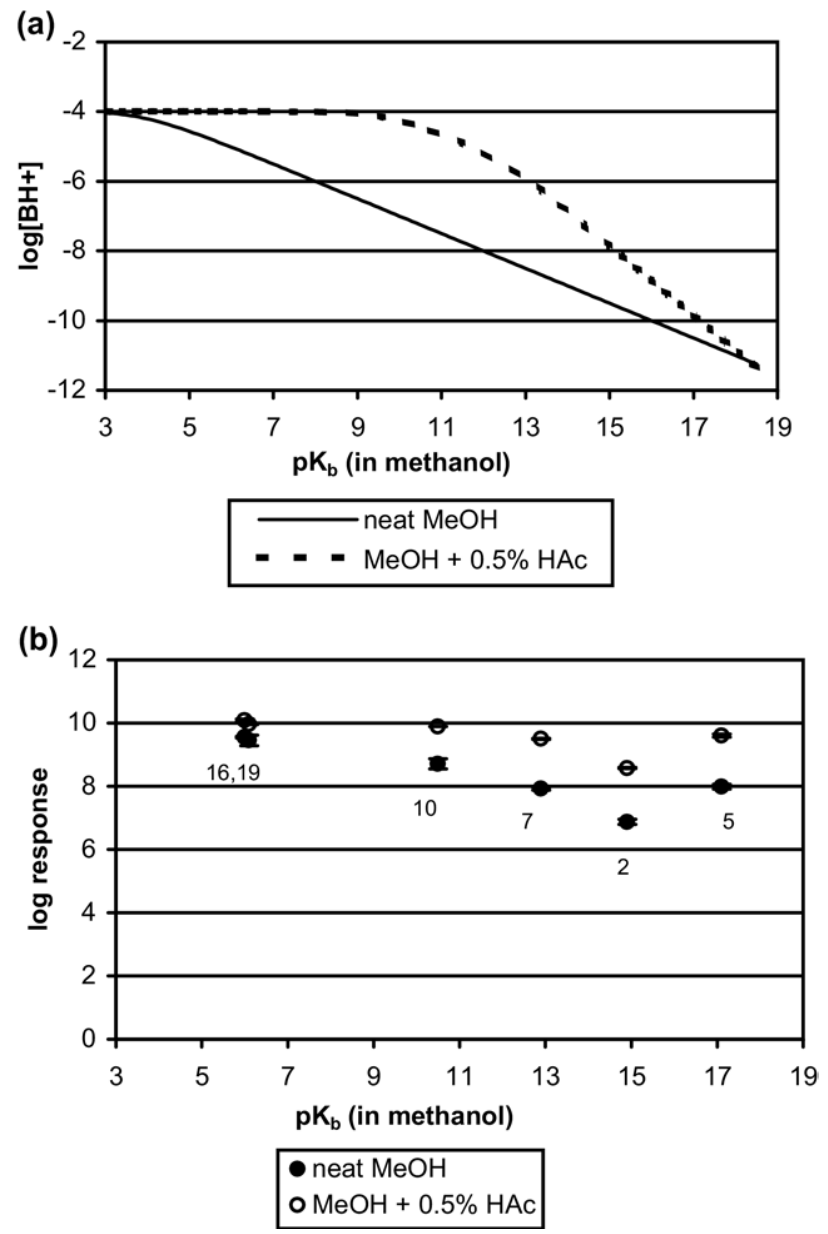

Figure 3. (a) The predicted effect of adding $0.5 \%$ acetic acid on electrospray ionization response. Each curve is plotted at concentration of protonated analyte $\left[\mathrm{BH}^{+}\right]$as a function of analyte $\mathrm{pK}_{\mathrm{b}}$. The predicted curve for neat methanol (solid line) was calculated from eq 3, where $\mathrm{C}_{\mathrm{i}}=100 \mu \mathrm{M}$ and $\mathrm{K}_{\mathrm{SH}}=3 \times 10^{-17}$. The predicted curve for methanol with $0.5 \%$ acetic acid was calculated from eqs 9 and 10 , where $\mathrm{C}_{\mathrm{i}}=100 \mu \mathrm{M}, \mathrm{K}_{\mathrm{SH}}=3 \times 10^{-17}, \mathrm{~K}_{\mathrm{a}, \mathrm{CH}_{3} \mathrm{COOH}}=2.34 \times$ $10^{-10}$, and $\mathrm{F}=0.087 \mathrm{M}$ (the formal concentration of $0.5 \%$ acetic acid). (b) Electrospray response as a function of $\mathrm{pK}_{\mathrm{b}}$ in neat methanol and methanol with $0.5 \%$ acetic acid for a subset of molecules from Table 1. Each analyte was analyzed separately in the two different solvents. For these data, the error bars represent \pm 1 standard deviation for triplicate injections. All data were collected in a single run.

The general shape of the predicted (Figure 3a) and observed (Figure $3 \mathrm{~b}$ ) curves for response versus $\mathrm{pK}_{\mathrm{b}}$ in neat and acidified methanol is similar. Furthermore, the prediction that the neat methanol and acidified methanol curves will converge at low $\mathrm{pK}_{\mathrm{b}}$ values also appears to hold true (Figure $3 b$ ). Response of analytes with high $\mathrm{pK}_{\mathrm{b}}$ values is enhanced significantly by the addition of acid, while analytes with low $\mathrm{pK}_{\mathrm{b}}$ values, those for which the protonated form would be favored even in neat methanol solution, the acidification of the solvent has a much less significant effect.

There are several ways in which the predicted and observed data displayed in Figure 3 do not agree. First, the responses in both neat methanol and acidified methanol are higher than predicted for Compound 5. The reason for this enhanced response is not known. Second, the magnitude of the difference between the neat and acidified methanol curves in the experimental data (Figure $3 b$ ) is much less significant than is the difference between the two predicted curves (Figure 3a). The similarity between the experimentally measured curves for neat methanol and acidified methanol could be explained by the previously mentioned acidification of electrospray droplets $[15,16]$. If the electrospray droplets are more acidic than would be expected based on the bulk $\mathrm{pH}$, the magnitude of the effect of adding acetic acid to the electrospray solution would be less significant than predicted based on calculations for neat methanol compared to acidified methanol.

\section{Gas Phase Proton Transfer and Electrospray Response}

One of the questions to be addressed in this study was whether analytes that were poorly basic in solution but had high gas-phase basicities would have enhanced electrospray responses due to gas-phase proton transfer. Improvement in electrospray response as a consequence of gas-phase proton transfer has been predicted by other investigators $[4,5,8]$, and this rationalization is often used to explain trends in electrospray response.

The analytes employed in these studies (Table 1) all have higher gas-phase proton affinities than that of methanol $(724.5 \mathrm{~kJ} / \mathrm{mol})$. Thus, if gas-phase proton transfer reactions between the analyte and the solvent such as that proposed in eq 11 were favorable, all of the analytes in this study would be expected to be highly responsive. Clearly, this is not the case. The analytes with high gas-phase basicities investigated in this study were highly responsive only if they also had low $p K_{b}$ values (Table 1). A number of analytes with relatively high gas-phase basicity values (in comparison to other analytes investigated), for example Compounds 5, 6, and 7, had relatively poor electrospray response. Response for these compounds appeared to be correlated with basicity in solution rather than in gas phase.

The observation of a correlation between electrospray response and basicity in solution is somewhat surprising given the current focus in the literature on the importance of gas-phase proton transfer in electrospray process. It is certainly not possible to rule out some contribution of gas-phase proton transfer to charging, but, at least for the analytes investigated here, it seems that in solution basicity is of greater significance than gas-phase basicity. One possible explanation for this observation is that analytes already charged in the electrospray solution are more likely to be transferred into the gas phase than those that are neutral. This suggestion seems logical if desolvation occurs through ion evaporation [11], such that ions enter the gas phase due to Coulombic repulsion on very small droplet surfaces. It has also previously been suggested 
that the small "offspring" droplets produced by later fissioning events in electrospray become enriched in charged analytes due to uneven fissioning of mass and charge [19]. It is these small offspring droplets that produce gas-phase ions with greatest efficiency. Thus, the effect of uneven fissioning of mass and charge in electrospray droplets may be further bias toward the production of gas-phase ions from charged rather than neutral ions.

One final question of importance regarding gasphase proton transfer in these studies is whether the enhanced response observed upon addition of acetic acid to the analyte solution (Figures 2 and 3) could be due to increased gas-phase proton transfer to the analyte. This might indeed be expected to be the case if the quantity of protonating reagent (i.e., protonated methanol) necessary to conduct reactions such as that depicted in eq 11 were limiting. However, if gas-phase proton transfer were responsible for the enhancement in response that resulted from the addition of acetic acid, this effect would be expected to be similar for all of the analytes studied, given that they all have significantly higher gas-phase basicities than methanol. The observation that response was enhanced more significantly for analytes with higher $\mathrm{pK}_{\mathrm{b}}$ values than those with lower $\mathrm{pK}_{\mathrm{b}}$ values (Figure $3 \mathrm{~b}$ ) strongly suggests that a solution rather than gas-phase effect is responsible for the enhancement in response that occurs upon addition of acetic acid.

\section{Surface Activity and Electrospray Response}

Analytes with higher affinities for electrospray droplet surfaces (termed "surface active") generally have higher electrospray responses than those that reside in droplet interiors [1]. An important factor determining surface activity is analyte polarity; analytes with significant nonpolar portions are expected to preferentially exist at electrospray droplet surfaces, where these nonpolar regions can be desolvated. The relationship between surface activity and response was observed as early as 1983 in the investigations of Iribarne et al. of atmospheric pressure ion evaporation mass spectrometry [20]. Increased response for surface active analytes was predicted by Enke's equilibrium partitioning model based on the enhanced ability of such analytes to compete for the surface excess charge phase in electrospray droplets [21]. Indeed, the Enke group observed electrospray response to correlate linearly with the nonpolar surface area of small peptides, which was taken as a measure of surface activity [22]. More recently, several investigations of small acidic molecules have shown a correlation between electrospray response in the negative ion mode and partition coefficient between octanol and water $(\log P)[23,24]$, a measure of analyte polarity. Because computations with molecular modeling software can easily be used to calculate $\log \mathrm{P}$ from analyte structure, this relationship is a useful one.
For the studies described here, we have employed $\log \mathrm{P}$ as an estimate of surface activity to investigate the contributions of surface activity to responsiveness of the analytes in Table 1. A plot of response as a function of $\log \mathrm{P}$ (data not shown) indicated no clear relationship between these parameters. Thus, for the analytes investigated here, chargeability appears to be more of a determining factor for responsiveness than polarity. However, it is worth noting that the five most responsive analytes investigated here all had relatively high logP-values (Table 1). It is entirely possible that an analyte with a very $\operatorname{low} \log \mathrm{P}$ value (a highly polar analyte) could be poorly responsive to ESI-MS analysis even if protonation for that analyte were highly favored in solution. Such a result would be likely given all of the previous investigations that have demonstrated a relationship between measures of non-polar character and response to ESI-MS analysis.

\section{Conclusions}

In these experiments, the parameter that most effectively predicted responsiveness to ESI-MS analysis was the analyte's $\mathrm{pK}_{\mathrm{b}}$, a measure of its basicity in solution. Electrospray response correlated with analyte $\mathrm{pK}_{\mathrm{b}}$ for all of the species investigated. However, the results of this study also show that responsiveness to analysis with ESI-MS cannot be explained simply as a transfer or protonated analyte from solution to the gas-phase. Species with very high $\mathrm{pK}_{\mathrm{b}}$ values, for which the predicted concentration of the protonated form in the bulk solution is well below the detection limit for the analysis, were still detectable with the ESI mass spectrometer used in these studies. Some factor inherent to the electrospray process facilitates the protonation of these species to a far greater extent than can be predicted by proton transfer equilibria in the bulk solution. This enhancement of protonation is very fortunate, because it means that ESI-MS is a suitable technique for analysis of organic species with a wide range of $\mathrm{pK}_{\mathrm{b}}$ values.

The addition of acetic acid to the electrospray solvent improved the response of all of the analytes investigated. This improvement was more significant for the poorly responsive analytes (those with high $\mathrm{pK}_{\mathrm{b}}$ values), but response of the highly responsive analytes was also improved, albeit only slightly. Thus, based on these results, the common practice of adding acetic acid to the electrospray solvent for all analyses in the positive ion mode seems to be justified. The magnitude of the enhancement in response that occurs as a result of this addition will, however, differ depending on the characteristics of the analyte. For the analysis of species that are sufficiently basic in solution, the addition of acetic acid may not be a requirement.

Given that all of the analytes investigated here had higher proton affinities than that of the methanol solvent, it might have been expected that gas-phase proton transfer would play an important role in charging them. However, this did not appear to be the case. Electros- 
pray response was low for analytes that were poor bases in solution even if they had very high gas-phase basicity. On the basis of the experimental data presented here, it is not possible to ascertain with any degree of certainty the reason for the apparent lack of importance of gas-phase proton transfer in charging the analytes investigated. Given the current focus in the electrospray literature on gas-phase proton transfer as a mechanism of charging, this subject is worthy of further investigation.

\section{Acknowledgments}

The authors thank Dr. Chris Enke, Dr. Brent Dawson, Dr. Paul Kebarle, and Dr. Terri Quenzer for helpful discussions. They also thank to Maqueita Eleazer for technical assistance. Funding for this study was provided by a Cottrell College Science Award from Research Corporation and from the Camille and Henry Dreyfus Foundation (in the form of an assistantship to B.M.E.).

\section{References}

1. Cech, N. B.; Enke, C. G. Practical Implications of Some Recent Studies in Electrospray Ionization Fundamentals. Rev. Mass Spectrom. 2001, 20, 362-387.

2. Kebarle, P.; Tang, L. From Ions in Solution to Ions in the Gas Phase. Anal. Chem. 1993, 65, 972A-985A.

3. Cole, R. B. Some Tenets Pertaining to Electrospray Ionization Mass Spectrometry. J. Mass Spectrom. 2000, 35, 763-772.

4. Ikonomou, M. G.; Blades, A. T.; Kebarle, P. Investigations of the Electrospray Interface for Liquid Chromatography/Mass Spectrometry. Anal. Chem. 1990, 62, 957-967.

5. Yen, T.-Y.; Charles, J. M.; Voyksner, R. D. Processes That Affect Electrospray Ionization-Mass Spectrometry of Nucleobases and Nucleosides. J. Am. Soc. Mass Spectrom. 1996, 7, 1106-1108.

6. Amad, M. H.; Cech, N. B.; Jackson, G. S.; Enke, C. G. Importance of Gas-Phase Proton Affinities in Determining the Electrospray Ionization Response for Analytes and Solvents. J. Mass Spectrom. 2000, 35, 784-789.

7. Hautreux, M.; Hue, N.; Du Fou de Kerdaniel, A.; Zahir, A.; Malec, V.; Laprévote, O. Under Nondenaturing Solvent Conditions, the Mean
Charge State of a Multiply Charged Protein Ion Formed by Electrospray is Linearly Correlated with the Macromolecular Surface. Int. J. Mass Spectrom. 2004, 231, 131-137.

8. Ogorzalek Loo, R. R.; Smith, R. D. Investigations of the Gas-Phase Structure of Electrosprayed Proteins Using Ion-Molecule Reactions. J. Am. Soc. Mass Spectrom. 1994, 5, 221-229.

9. NIST, Nist Webbook 2008: http://webbook.nist.gov/chemistry; accessed $1 / 18 / 2008$.

10. Dole, M.; Mack, L. L.; Hines, R. L.; Mobley, R. C.; Ferguson, L. D.; Alice M. B. Molecular Beams of Macroions. J. Chem. Phys. 1968, 49, 2240-2249.

11. Iribarne, J. V.; Thomson, B. A. On the Evaporation of Charged Ions from Small Droplets. J Chem. Phys. 1976, 64, 2287-2294.

12. Rondini, S.; Longhi, P.; Mussini, P. R.; Mussini, T. Autoprotolysis Constants in Nonaqueous Solvents and Aqueous Organic Solvent Mixtures. Pure Appl. Chem. 1987, 59, 1693-1702.

13. Rived, F.; Marti, R.; Bosch, E.; Dissociation Constants of Neutral and Charged Acids in Methyl Alcohol. The Acid Strength Resolution. Anal. Chim. Acta 1998, 374, 309-324.

14. Van Berkel, G. J. Electrolytic Corrosion of a Stainless-Steel Electrospray Emitter Monitored Using an Electrospray-Photodiode Array System. J. Anal. Atom Spectrom. 1998, 13, 603-607.

15. Van Berkel, G. J.; Zhou, F.; Aronson, J. T. Changes in Bulk Solution pH Caused by the Inherent Controlled-Current Electrolytic Process of an Electrospray Source. Int. J. Mass Spectrom. Ion Processes 1997, 162, 55-67.

16. Zhou, S.; Prebyl, B. S.; Cook, K. D. Profiling pH Changes in the Electrospray Plume. Anal. Chem. 2002, 74, 4885-4888.

17. Mansoori, B. A.; Volmer, D. A.; Boyd, R. K. Wrong-Way-Round Electrospray Ionization of Amino Acids. Rapid Commun. Mass Spectrom. 1997, 11, 1120-1130.

18. Wu, Z.; Gao, W.; Phelps, M. A.; Wu, D.; Miller, D.; Dalton, J. T. Favorable Effects of Weak Acids on Negative-Ion Electrospray Ionization Mass Spectrometry. Anal. Chem. 2004, 76, 839-847.

19. Cech, N. B.; Enke, C. G. The Effect of Affinity for Charged Droplet Surfaces on the Fraction of Analyte Charged in the Electrospray Process. Anal. Chem. 2001, 73, 4632-4639.

20. Iribarne, J. V.; Dziedzic, P. J.; Thomson, B. A. Atmospheric Pressure Ion Evaporation-Mass Spectrometry. Int. J. Mass Spectrom. Ion Phys. 1983, 50, 331-347.

21. Enke, C. G. A Predictive Model for Matrix and Analyte Effects in Electrospray Ionization of Singly-Charged Ionic Analytes. Anal. Chem. 1997, 69, 4885-4893.

22. Cech, N. B.; Enke, C. G. Relating Electrospray Ionization Response to Nonpolar Character of Small Peptides. Anal. Chem. 2000, 72, 2717-2723.

23. Henriksen, T. R.; Juhler, R. K.; Svensmark, B.; Cech, N. B. The Relative Influences of Acidity and Polarity on Responsiveness of Small Organic Molecules to Analysis with Negative Ion Electrospray Ionization Mass Spectrometry (ESI-MS). J. Am. Soc. Mass Spectrom. 2005, 16, 446-455.

24. Schug, K.; McNair, H. M. Adduct Formation in Electrospray Ionization. Part I: Common Acidic Pharmaceuticals. J. Sep. Sci. 2002, 25, 760-766. 